\title{
Spotlight v: Transition finance - financing the journey towards sustainable development
}

\author{
Olivier Cattaneo \& Cecilia Piemonte, OECD
}

To support the implementation of the Addis Ababa Action Agenda (AAAA), in its communiqué issued at its 2017 High Level Meeting, the Development Assistance Committee (DAC) set an objective "to better understand the broad catalytic effect of official support and other resources by understanding the interlinkages among official development assistance (ODA), partner countries' domestic resources, private investment, remittances, philanthropy, trade finance and export credits, and other sources of finance", and to "continue to collaborate with other experts within the OECD and beyond in order to have a global overview and outlook on financing for development"97.

The work on transition finance responds to this call, exploring the availability and interactions of the different sources of financing for sustainable development (public and private, external and domestic) as countries develop and reach higher levels of income. Indeed, the intention of the OECD's work on transition finance is to help DAC members manage transition in partner countries better and, as ODA is progressively phased out, enhance the resilience of their efforts by avoiding financing gaps or socio-economic setbacks. As part of the work stream, seven pilot studies ${ }^{98}$ on countries illustrative of different transition phases, challenges and geographies have been produced ${ }^{99}$. These form the basis of the following analysis ${ }^{100}$.

97 OECD Development Assistance Committee 2017: para. 15.

98 Cabo Verde, Chile, Lebanon, Solomon Islands, Uganda, Vietnam, Zambia.

99 In addition, a working paper that outlines the analytical basis of this framework, various fact sheets and an online dashboard have been developed. All products will be published within the Transition Finance Compendium (OECD, forthcoming).

100 The methodological approach for the case studies followed an 'ABC framework' for transition finance diagnostics, which involves: Assessing the transition context in the country; Benchmarking the substitution effects between public, private, domestic and international resources; and Counselling on how development partners can help phase out ODA and secure the progressive growth of other sources of finance. 
As showcased in Figure 2, as countries transition (with the rise in their GNI per capita) they lose access to certain types of financing, but gain access to a broader variety of actors, tools and instruments.

Figure 2: DAC, non-DAC OECD members and multilateral agencies' outflows, 2013-2017 net disbursements, 2017 prices

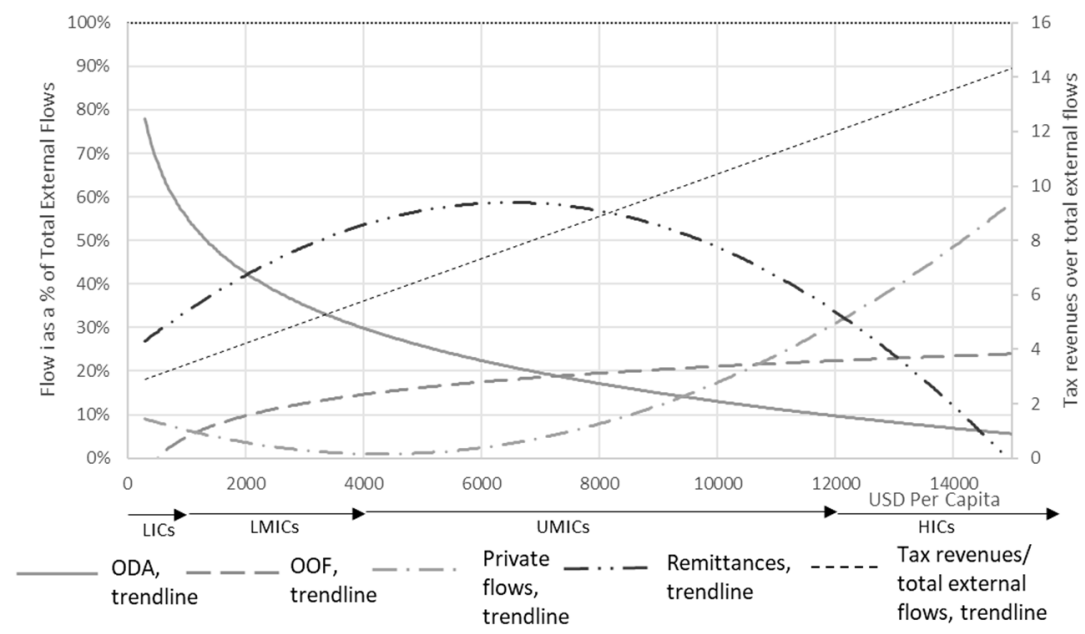

Source: Authors' calculations ${ }^{101}$

This illustrates two main trends:

(i) There is a relative substitution of external with domestic resources (the latter becoming more and more important in relation to the former). From the onset, domestic resources are the largest source of finance for the economy - with a 4 to 1 ratio of tax revenues/external flows. This ratio keeps increasing, however, with tax revenues representing more than 12 times the value of external flows as the country reaches high-income status. Domestic resource mobilisation is therefore a key component of sustainable national financing strategies, and should remain a primary objective of ODA;

(ii) There is a relative substitution of external public with external private resources. Highly dependent on public external support (mainly ODA) in early

101 Calculations based on OECD (2018d 'Creditor Reporting System' database) for ODA, OOF flows, and private flows, World Bank (2018 'migration and remittances data'), UNUWIDER (2018, 'tax revenues' database) and IMF (2017, 'Balance of Payments' database) for FDI, portfolio investments, and long-term and short-term debt. 
stages of transition (lower levels of GNI per capita), countries progressively move towards private financing of their economy. Public financing itself evolves, with a progressive substitution of ODA with OOF; then private flows (foreign direct investments and remittances) take the leading financial role.

\section{Graduation from ODA eligibility}

One of the pilot studies in the work stream explored the specific ODA graduation milestone by looking at the case of Chile ${ }^{102}$. The experience of Chile is particularly interesting from a transition finance perspective as most of the recent ODA graduates are either SIDS, oil-exporting countries or countries in the EU neighbourhood. After decades of continuous economic growth, Chile reached HIC status in 2011, a year after it joined the OECD, and continued to be eligible for ODA until $2017^{103}$.

First, the study showed that ODA flows to Chile had remained relatively low from the early 1970s onwards and until its ODA graduation in 2017: the last projects were not concessional and targeted renewable energy. Second, the study found that technical cooperation, even if low (25 million USD on average per year in 2010-2017), was considered important to the country. Nonetheless, most projects were discontinued and not replaced by domestic equivalents in the absence of allocation in the national budget. Finally, the study observed considerable disparities between economic and social growth and inequalities, which prompted the recent massive street protests throughout Chile, and questioned the prioritisation of DAC interventions prior to Chile's graduation.

In sum, insufficient efforts were made to strengthen the resilience of $\mathrm{ODA}^{104}$, in particular with regard to domestic resource mobilisation (e.g. to address inequalities), the continuity of technical assistance programmes through budgeting or other forms of financing (e.g. through regional programmes), or the sustainability of private financing. More efforts could also be dedicated to tapping the strong potential of Chile in triangular cooperation and as a provider of development cooperation.

Indeed, the results of the seven case studies led to the overall conclusion ${ }^{105}$ that each transition milestone needs to be equally prepared. There is no single milestone, whether legal or income-based, that is more important than others.

102 Cattaneo et al. 2020.

103 The DAC graduation rules stipulate that a country is removed from its list of ODA recipients when it exceeds the high-income threshold (as measured by GNI per capita) for three consecutive years at the time of the committee's review, which itself takes place every three years.

104 The concept "resilience of ODA" refers to the best alternative use of ODA resources in order to perennialise its effects.

105 OECD forthcoming. 
Moreover, efforts to strengthen the resilience of ODA should be increased all along the development continuum.

\section{What could the DAC do to manage graduation from ODA eligibility better?}

Specific mechanisms and tools could be developed to support ODA graduation: these could include better defined and targeted technical assistance, as well as transition loans or grants. While the DAC could maintain the GNI per capita criterion for ODA graduation ${ }^{106}$, other warning indicators could be highlighted to apprehend the countries' situation better with regard to specific vulnerabilities, such as climate or inequalities, and guide ODA efforts close to graduation. Additionally, the DAC could usefully create a mechanism for preparing graduation better as well as promoting continuous dialogue and peer-learning after graduation from ODA. Such a 'Graduates' Club' would allow for monitoring of socio-economic progress after graduation, tracking non-ODA flows, discussing experiences and advising recent or future graduates, developing new relations with DAC donors beyond ODA, assisting access to other types of finance and technical assistance, and enhancing a country's capacity to become a donor. Finally, the DAC should develop new channels for sharing expertise and technology as well as for peer-to-peer learning. These could include: (i) better use of multilateral (including global funds) and regional financing and support mechanisms (including deep trade agreements) to sustain inclusive growth; (ii) the identification of new institutional partners for preserving budgetary allocations in favour of jointly identified priorities (e.g. climate change); and (iii) the reform of former channels of cooperation to harness new tasks, such as triangular cooperation. ${ }^{107}$

106 So far, this criterion has not been called into question by the DAC because of its simplicity of use and utility with respect to universality, comparability and other practical reasons, e.g. availability of data in developing countries.

107 All key products of the OECD work stream on transition finance, including the detailed results and summaries of the seven country studies and an online tool for conducting additional transition finance analyses, are available online at: www.oecd.org/dac/transition-finance-toolkit. Forthcoming products will also be published here. 